\title{
Indigo Naturalis Suppresses Colonic Oxidative Stress and Th1/Th17 Responses of DSS-Induced Colitis in Mice
}

\author{
Hai-tao Xiao $\mathbb{D}^{1,2,3}{ }^{1,3 i a o}$ Peng, ${ }^{4}$ Bo Wen, ${ }^{2,3}$ Dong-dong Hu, ${ }^{2}$ Xiao-peng Hu, ${ }^{1}$ \\ Xiang-chun Shen, ${ }^{3}$ Zhi-gang Liu, ${ }^{1}$ Zhen-dan He ${ }^{D},{ }^{1}$ and Zhao-xiang Bian ${ }^{2}{ }^{2,5}$ \\ ${ }^{1}$ School of Pharmaceutical Sciences, Guangdong Key Laboratory for Genome Stability \& Human Disease Prevention, Shenzhen Key \\ Laboratory of Novel Natural Health Care Products, Innovation Platform for Natural Small Molecule Drugs, Engineering Laboratory \\ of Shenzhen Natural Small Molecule Innovative Drugs, Health Science Center, Shenzhen University, Shenzhen 518060, China \\ ${ }^{2}$ School of Chinese Medicine, Hong Kong Baptist University, Kowloon, Hong Kong \\ ${ }^{3}$ The Key Laboratory of Pharmacology and Druggability for Natural Medicines, Department of Education, \\ Guizhou Medical University, Guiyang, Guizhou 550025, China \\ ${ }^{4}$ Department of Pharmacy, Peking University Shenzhen Hospital, Shenzhen 518036, China \\ ${ }^{5}$ Shenzhen Research Institute and Continuing Education, Hong Kong Baptist University, Shenzhen 518060, China
}

Correspondence should be addressed to Zhen-dan He; hezhendan@szu.edu.cn and Zhao-xiang Bian; bianzxiang@gmail.com

Received 21 February 2019; Revised 4 May 2019; Accepted 25 June 2019; Published 13 October 2019

Academic Editor: Ilaria Peluso

Copyright (c) 2019 Hai-tao Xiao et al. This is an open access article distributed under the Creative Commons Attribution License, which permits unrestricted use, distribution, and reproduction in any medium, provided the original work is properly cited.

\begin{abstract}
Indigo naturalis (also known as Qing-dai, or QD), a traditional Chinese medicine, has been widely used as an anticolitis regimen in the clinical practice of Chinese medicine. However, the precise mechanisms behind its efficacy remain unknown. We investigated the protective effects and associated molecular mechanisms of QD in DSS-induced colitis in mice. We found that QD administration attenuated DSS-induced colon shortening, tissue damage, and the disease activity index during the onset of colitis. Moreover, QD administration significantly suppressed colonic MPO activity and increased the activities of colonic T-SOD, CAT, and GSH-Px, as well the expression of p-AMPK and Nrf-2 in colon tissues of colitic mice. In addition, QD was capable of reducing the colonic Th1 and Th17 cell cytokines, the frequencies of Th1 and Th17 cells, and the phosphorylation of p-STAT1 and p-STAT3 in the mesenteric lymph nodes of colitic mice. An in vitro assay showed that QD significantly suppressed the differentiation of Th1 and Th17 cells. These findings suggest that QD has the potential to alleviate experimental colitis by suppressing colonic oxidative stress and restraining colonic Th1/Th17 responses, which are associated with activating AMPK/Nrf-2 signals and inhibiting STAT1/STAT3 signals, respectively. These findings also support QD as an effective regimen in the treatment of IBD.
\end{abstract}

\section{Introduction}

Inflammatory bowel disease (IBD), such as ulcerative colitis and Crohn's disease, represents a group of lifelong recurrent relapsing-remitting intestinal disorders, which are associated with gastrointestinal symptoms, such as weight loss, diarrhea, abdominal pain, internal bleeding, and extensive colonic mucosal and submucosal damage $[1,2]$. IBD patients are being diagnosed worldwide; its in-patient admission rate is stabilizing at around $0.3 \%$ in Western countries and is rising rapidly in Asia, in parallel with westernization [3]. For example, the in-patient admission rate of
IBD in the Yunnan province of China has risen 19.4-fold from 1998 to 2013 [4]. With no cure, its high hospitalization costs and increasing prevalence place an increased stress on healthcare systems. Current medical therapies for IBD focus mainly on inducing remission and preventing relapse, and aminosalicylates, corticosteroids, thiopurines, and biological agents are commonly recommended as the standard treatments for IBD patients [1]. However, these agents are not very satisfactory and have various side effects that limit their therapeutic benefits, particularly for longterm therapy [5]. For example, long-term treatment of aminosalicylates and corticosteroids could induce depression, 
growth retardation, osteoporosis, and hypertension [5]; and thiopurines such as azathioprine and 6-mercaptopurine could induce bone marrow suppression, pancreatitis, and hepatic toxicity [6]. Thus, there is still a considerable need to improve the treatment of IBD, and significant research efforts are underway to address this unmet need.

Over the past two decades, the understanding of IBD pathogenesis has progressed rapidly, but it is still not completely understood. However, impaired endogenous enzymatic antioxidants, including superoxide dismutases (SOD), catalases (CAT), glutathione peroxidases (GSH-Px), and glutathione reductases (GRx), and the enhanced production of free radicals, such as reactive oxygen species (ROS) and reactive nitrogen species (RNS), are commonly associated with the development of IBD [7]. Excessive free radical production results in considerable colonic inflammation. Clinically, patients with colitis exhibit an overproduction of ROS, which has a pivotal role in IBD pathogenesis [8]. In addition, the dysregulation of mucosal $\mathrm{CD} 4^{+} \mathrm{T}$ cells also plays a major role in the development of IBD, which impedes the resolution of inflammation and instead results in disease perpetuation and tissue injury [9]. $\mathrm{CD}^{+} \mathrm{T}$ cells mainly contain effector $\mathrm{CD}^{+} \mathrm{T}$ cells such as $\mathrm{T}$ helper 1 (Th1), Th2, Th17, and regulatory $\mathrm{T}$ cells (Tregs). Studies have shown that intestinal immune homeostasis depends on the regulation and balance of these $\mathrm{CD} 4^{+} \mathrm{T}$ cell subgroups, and the deregulated overexpansion and activation of Th1 and Th17 cells in relation to Tregs can lead to intestinal inflammation, such as IBD [10-12]. Since Th1 and Th17 cells could secrete large amounts of proinflammatory cytokines such as IFN- $\gamma$, TNF- $\alpha$, IL- $1 \beta$, and IL- 17 , resulting in persistent intestinal inflammation [13], medications that can suppress colonic oxidative status and inhibit Th1/Th17 responses would be shown to be clinically effective.

Indigo naturalis (in China, also known as Qing Dai, or QD), a dark-blue powder, is sourced from the leaves and branches of various indigo-producing plants, such as Baphicacanthus cusia (Nees) Bremek, Indigofera tinctoria L., Isatis indigotica Fort, Polygonum tinctoria Ait, and Strobilanthes cusia (Nees) Kuntze [14]. In traditional Chinese medicine (TCM), QD has been widely used for treating various infectious and inflammatory diseases, such as enteritis, carbuncles, eczema, and psoriasis $[14,15]$. A recent multicenter randomized controlled trial and retrospective observational studies have demonstrated that QD could be effective in inducing mucosal healing in patients with UC and intractable UC [16-18]. In addition, we prescribed a QD-predominant (QDP) herbal medicinal formula to our out-patients with intractable UC who failed to respond to treatment with 5-ASA, prednisolone, or infliximab and achieved a good curative effect [19]. In an animal experiment model, Kawai et al. revealed that QD was effective in ameliorating DSS-induced colonic inflammation, and the mechanism was associated with increasing IL-10-producing $\mathrm{CD}^{+}$ $\mathrm{T}$ cells and IL-22-producing $\mathrm{CD}^{-} \mathrm{ROR} \gamma \mathrm{t}^{+}$cells via aryl hydrocarbon receptor activation [20]. However, it is unclear whether QD can ameliorate intestinal inflammation by targeting colonic oxidative stress and effector Th1/Th17 cells. In the present study, we investigate the therapeutic effects of QD on DSS-induced acute colitis in mice and examine its regulatory mechanisms on colonic oxidative stress and effector Th1/Th17 cells.

\section{Materials and Methods}

2.1. Reagents. DSS (molecular weight: 36,000 to 50,000 ) was purchased from MP Biomedicals (Santa Ana, USA). Dimethyl sulphoxide (DMSO), sulfasalazine (SASP) (purity: 98\%), hexadecyltrimethylammonium bromide, hematoxylin, eosin, and $o$-dianisidine dihydrochloride were purchased from Sigma-Aldrich (St. Louis, MO, USA). Fetal bovine serum, L-glutamine, penicillin, streptomycin, and minimum essential medium were purchased from Invitrogen (Carlsbad, CA, USA). CD4 ${ }^{+} \mathrm{CD} 2 \mathrm{~L}^{+} \mathrm{T}$ Cell Isolation Kits were purchased from Miltenyi Biotec (Bergisch Gladbach, Germany). The fluorescent antibodies CD4, IFN- $\gamma$, IL-17A, FoxP $_{3}$, and $\mathrm{CD} 3 / \mathrm{CD} 28$ were obtained from eBioscience (San Diego, CA, USA) or BD Biosciences (San Jose, CA, USA). Antibodies against p-AMPK, AMPK, Nrf-2, p-STAT1, STAT1, p-STAT3, STAT3, and $\beta$-actin were supplied from Cell Signaling Technology Inc. (Beverly, MA, USA). Recombinant mouse IL-12, IL- 6 , and TGF- $\beta$ proteins and antibodies IL- 4 and IFN- $\gamma$ were purchased from BioLegend (San Diego, CA, USA). IFN- $\gamma$, IL-17A/F, TNF- $\alpha$, and IL- $1 \beta$ ELISA kits were purchased from eBioscience (San Diego, CA). Total superoxide dismutases (T-SOD), CAT, and GSH-Px colorimetric activity assay kits were purchased from Jiancheng Bioengineering Institute (Nanjing, China). An enhanced chemiluminescence kit was supplied by GE Healthcare BioSciences Corp. (Piscataway, NJ, USA).

2.2. Indigo Naturalis. Indigo naturalis (QD) was obtained from the dispensary of the TCM, Clinical Division, School of Chinese Medicine, Hong Kong Baptist University, Hong Kong, which was derived from the herbs of Strobilanthes cusia (Nees) Kuntze. The authentication and quality control of QD were performed based on the requirements of the Chinese Pharmacopoeia [21]. The voucher specimen (voucher number: TCM-0110-Q01) was stored in the Research Laboratory, School of Chinese Medicine, Hong Kong Baptist University, Hong Kong. To identify the components in QD, the sample was weighed exactly, ultrasonically extracted with DMSO, and filtered through a syringe filter for subsequent UPLC-QTO-MS analysis.

2.3. UPLC-QTOF-MS Analysis of QD. The components in QD were identified using the UPLC-QTOF-MS method, with a small change in the composition of the mobile phase [22]. The mobile phase for the analysis of QD consisted of (A) $0.1 \%$ formic acid in water and (B) $0.1 \%$ formic acid in acetonitrile. A linear gradient was optimized as follows (flow rate, $0.40 \mathrm{~mL} / \mathrm{min}$ ): $0-2.5 \mathrm{~min}, 2-5 \% \mathrm{~B} ; 2.5-10 \mathrm{~min}$, 5-35\% B; 10-20 min, 35-75\% B; 20-23 min, 75-100\% B; $23-26 \mathrm{~min}, 100 \% \mathrm{~B} ; 26-26.1 \mathrm{~min}, 100-2 \% \mathrm{~B}$; and $26.1-$ $30 \mathrm{~min}, 2 \% \mathrm{~B}$.

2.4. Animals. Seven to eight-week-old male C57BL/6 mice weighing 20-24g were purchased from the Laboratory Animal Services Center, at the Chinese University of Hong Kong. 
The animals were fed a standard rodent diet with free access to water and were kept in rooms maintained at $22 \pm 1^{\circ} \mathrm{C}$ with a $12 \mathrm{~h}$ light/dark cycle following international recommendations. All animal procedures and experiments were carried out according to the "Institutional Guidelines and Animal Ordinance" (Department of Health, Hong Kong Special Administrative Region) and approved by the related ethical regulations of Animal Ethics Committees of Hong Kong Baptist University.

2.5. Induction of Colitis and Treatment. Colitis was induced by DSS administration as per our previous description in [23]. Briefly, the colitis was induced by feeding the mice $2 \%$ DSS drinking water for five days. After five days of DSS administration, the colitic mice were subjected to a disease activity index (DAI) test and selected for the investigation. The colitic mice were randomly divided into the DSS model group, the SASP-treated group, and the QD-treated groups with two different dosages. In parallel, a vehicle control group was set up to receive drinking water without DSS throughout the experimental period. QD was orally administrated to the mice, with a dosage of 0.5 and $1 \mathrm{~g} / \mathrm{kg} /$ day for 7 days according to the preliminary experiment. SASP was selected as a reference positive agent, and its dosage was set to $0.20 \mathrm{~g} / \mathrm{kg} / \mathrm{day}$ according to the literature $[24,25]$. SASP and QD were freshly suspended in $0.5 \%$ CMC-Na solution and orally administered to the mice for seven days. The vehicletreated control group and DSS model group received the same volume of the dosing vehicle.

2.6. Evaluation of Colitis. Body weight, stool consistency, and stool bleeding were recorded daily. The DAI was determined by combining the scores for body weight, stool consistency, and stool bleeding. At the end of the experiment, colonic segments were excised to measure the length from the ileocecal junction to the anal verge. Subsequently, colonic tissues were embedded in paraffin, and $5 \mathrm{~mm}$ sections were stained with hematoxylin and eosin (H\&E) and scored in a blind fashion by an experienced pathologist. Colonic MPO activity was also measured as described in our previous study [23].

2.7. RNA Extraction and Quantitative PCR Analysis. The total mRNA of the colon tissue was extracted using TRIzol ${ }^{\circledR}$ (Invitrogen). The cDNA was synthesized using a TaKaRa RNA PCR Kit (AMV) Ver. 3.0 (TaKaRa Bio Inc., Dalian, China), and quantitative real-time PCR (qPCR) was detected using the ABI 7500 Real-Time PCR System, with a SYBR Green Master Mix (Applied Biosystems, Foster, CA, USA). Relative quantification of mRNA expression was normalized with $\beta$-actin control and analyzed using the delta-delta $\mathrm{Ct}$ $\left(2^{-\Delta \Delta} \mathrm{CT}\right)$ method. Primer sequences (forward/reverse) were listed as follows: mouse $\beta$-actin, forward $5^{\prime}$-TGT CCA CCT TCC AGC AGA TGT-3' and reverse $5^{\prime}$-AGC TCA GTA ACA GTC CGC CTA GA-3'; mouse ROR $\gamma \mathrm{t}$, forward $5^{\prime}$-GGA GCT CTG CCA GAA TGA GC-3' and reverse $5^{\prime}$-CAA GGC TCG AAA CAG CTC CAC-3'; mouse T-bet, forward $5^{\prime}$-AGC AAG GAC GGC GAA TGT $\mathrm{T}^{\prime} 3^{\prime}$ and reverse $5^{\prime}$-GGG TGG ACA TAT AAG
CGG TTC-3'; mouse IL-17A, forward 5'-TCG AGA AGA TGC TGG TGG GT- $3^{\prime}$ and reverse $5^{\prime}$-CTC TGT TTA GGC TGC CTG GC- $3^{\prime}$; mouse IFN- $\gamma$, forward $5^{\prime}$-TGA GTA TTG CCA AGT TTG AGG TCA-3' and reverse 5'-CGG CAA CAG CTG GTG GAC-3'; and mouse Tbet, forward $5^{\prime}$-AGC AAG GAC GGC GAA TGT T-3' and reverse $5^{\prime}$-GGG TGG ACA TAT AAG CGG TTC-3'.

2.8. CD4 T Cell Differentiation. Naïve CD4 T cells were purified using $\mathrm{CD}^{+} \mathrm{CD} 2 \mathrm{~L}^{+} \mathrm{T}$ Cell Isolation Kits and diluted to the density of $1 \times 10^{6}$ cells per mL in RPML-1640 medium. $1 \times 10^{5}$ naïve CD4 $\mathrm{T}$ cells were seeded per well into a 96well plate and stimulated with plate-bound anti-CD3e $\mathrm{Ab}$ $(5 \mu \mathrm{g} / \mathrm{mL})$, soluble anti-CD28 Ab $(2 \mu \mathrm{g} / \mathrm{mL})$, and different polarized conditions, in the presence of indicated concentrations of QD for $72 \mathrm{~h}$ at $37^{\circ} \mathrm{C}$. To generate Th1 cells, naïve CD4 T cells were cultured with IL-12 (50 ng/mL) and antiIL-4 Ab $(1 \mu \mathrm{g} / \mathrm{mL})$. For generating Th17 cells, naïve CD4 T cells were cultured with IL-6 (100 ng/mL), TGF- $\beta(2 \mathrm{ng} / \mathrm{mL})$, anti-IFN- $\gamma(1 \mu \mathrm{g} / \mathrm{mL})$, and anti-IL-4 Ab $(1 \mu \mathrm{g} / \mathrm{mL})$.

2.9. Intracellular Staining. Mesenteric lymph node cells from DSS-colitis mice were collected after the experiment, and polarized naïve CD4 $\mathrm{T}$ cells were first restimulated with phorbol myristate acetate (PMA, $50 \mathrm{ng} / \mathrm{mL}$ ) and ionomycin ( $500 \mathrm{ng} / \mathrm{mL}$ ) in the presence of GolgiPlug (BD Biosciences) for $5 \mathrm{~h}$ and then stained with anti-CD4 and IFN- $\gamma$ or IL-17A or $\mathrm{FoxP}_{3} \mathrm{Ab}$ for $45 \mathrm{~min}$ after blocking FcR. Acquisition was performed using FACS, and data analysis was conducted using FlowJo software (Tree Star Inc., Ashland, OR).

2.10. ELISA and Immunoblot. Colon tissues and lymphocytes were homogenized or lysed in an ice-cold RIPA lysis buffer (Cell Signaling Technology, Danvers, MA, USA) with a $1 \%$ $(v / v)$ protease and $10 \%(v / v)$ phosphatase inhibitor cocktail (Roche, Basel, Switzerland) and centrifuged at 16,000 g at $4^{\circ} \mathrm{C}$ for $15 \mathrm{~min}$. The supernatants were collected to determine the concentrations of the cytokines IFN- $\gamma$, IL-17A/F, TNF- $\alpha$, and IL- $1 \beta$, as well as the oxidative stress markers T-SOD, CAT, and GSH-Px, using commercial ELISA kits according to the manufacturers' instructions. The protein expressions of p-AMPK, AMPK, Nrf-2, p-STAT1, STAT1, p-STAT3, STAT3, and $\beta$-actin were analyzed using Western blotting as described elsewhere.

2.11. Statistical Analysis. The data are presented as mean value \pm standard deviation. Statistical significances were evaluated using one-way ANOVA, followed by Duncan's multiple range tests. GraphPad Prism 5.0 software (GraphPad Software Inc., San Diego, CA, USA) was used for all calculations, and $p<.05$ was considered statistically significant.

\section{Results}

3.1. Identification of Major Components in QD by UPLCQTOF-MS. Under the optimized conditions [26], the major constituents of QD were well separated and detected within 
TABLE 1: Main components identified in QD.

\begin{tabular}{|c|c|c|c|}
\hline Peak & $\mathrm{tR}(\mathrm{min})$ & Assigned identity & Molecular formula \\
\hline 1 & 0.976 & Butanedioic acid & $\mathrm{C}_{4} \mathrm{H}_{6} \mathrm{O}_{4}$ \\
\hline 2 & 5.771 & Isatin & $\mathrm{C}_{8} \mathrm{H}_{5} \mathrm{NO}_{2}$ \\
\hline 3 & 5.916 & 2,3-Dihydro-4-hydroxy-2-oxo-1H-indole-3-acetic acid & $\mathrm{C}_{10} \mathrm{H}_{8} \mathrm{~N}_{2} \mathrm{O}_{2}$ \\
\hline 4 & 6.497 & Deoxyvascinone & $\mathrm{C}_{11} \mathrm{H}_{10} \mathrm{~N}_{2} \mathrm{O}$ \\
\hline 5 & 7.717 & 10H-indolo $[3,2-b]$ quinoline & $\mathrm{C}_{15} \mathrm{H}_{10} \mathrm{~N}_{2}$ \\
\hline 6 & 8.884 & 3-(2-Hydroxyphenyl)-4(3H)-quinazolinone & $\mathrm{C}_{14} \mathrm{H}_{10} \mathrm{~N}_{2} \mathrm{O}_{2}$ \\
\hline 7 & 8.998 & $10 \mathrm{H}$-indolo[3,2-b]quinoline-11-carboxylic acid amide & $\mathrm{C}_{16} \mathrm{H}_{11} \mathrm{~N}_{3} \mathrm{O}$ \\
\hline 8 & 9.597 & Tryptanthrin & $\mathrm{C}_{15} \mathrm{H}_{8} \mathrm{~N}_{2} \mathrm{O}_{2}$ \\
\hline 9 & 11.491 & Syringin & $\mathrm{C}_{17} \mathrm{H}_{24} \mathrm{O}_{9}$ \\
\hline 10 & 11.902 & 3-(2-Carboxyphenyl)-4(3H)-quinazolinone & $\mathrm{C}_{15} \mathrm{H}_{10} \mathrm{~N}_{2} \mathrm{O}_{3}$ \\
\hline 11 & 13.250 & Indigo & $\mathrm{C}_{16} \mathrm{H}_{10} \mathrm{~N}_{2} \mathrm{O}_{2}$ \\
\hline 12 & 14.006 & Indican & $\mathrm{C}_{14} \mathrm{H}_{17} \mathrm{NO}_{6}$ \\
\hline 13 & 14.158 & Indirubin & $\mathrm{C}_{16} \mathrm{H}_{10} \mathrm{~N}_{2} \mathrm{O}_{2}$ \\
\hline 14 & 14.640 & 2-[Cyano(3-indolyl)methylene]-3-indolone & $\mathrm{C}_{18} \mathrm{H}_{11} \mathrm{~N}_{3} \mathrm{O}$ \\
\hline 15 & 19.153 & Octadecanoic acid & $\mathrm{C}_{18} \mathrm{H}_{36} \mathrm{O}_{3}$ \\
\hline 16 & 19.332 & Bisindigotin & $\mathrm{C}_{32} \mathrm{H}_{18} \mathrm{~N}_{4} \mathrm{O}_{2}$ \\
\hline 17 & 20.554 & Qingdainone & $\mathrm{C}_{23} \mathrm{H}_{13} \mathrm{~N}_{3} \mathrm{O}_{2}$ \\
\hline 18 & 20.848 & Betulin & $\mathrm{C}_{30} \mathrm{H}_{50} \mathrm{O}_{2}$ \\
\hline 19 & 21.460 & Sugiol & $\mathrm{C}_{20} \mathrm{H}_{28} \mathrm{O}_{2}$ \\
\hline 20 & 22.815 & Rotenol & $\mathrm{C}_{23} \mathrm{H}_{24} \mathrm{O}_{6}$ \\
\hline 21 & 23.433 & Sitosterol & $\mathrm{C}_{32} \mathrm{H}_{53} \mathrm{~N}_{7} \mathrm{O}_{2}$ \\
\hline 22 & 24.699 & Daucosterol & $\mathrm{C}_{35} \mathrm{H}_{60} \mathrm{O}_{6}$ \\
\hline 23 & 26.831 & Clerosterol & $\mathrm{C}_{29} \mathrm{H}_{48} \mathrm{O}$ \\
\hline
\end{tabular}

30 min under positive ESI-MS ion mode (as shown in supplementary Fig. 1). Table 1 shows that a comparison of the retention time (tR), mass fragment ions $(\mathrm{m} / z)$, and UV absorption characteristics (lambda max) with those of chemical compounds in the literature tentatively identified 23 peak signal chemical components.

3.2. QD Ameliorated the Severity of DSS-Induced Colitis in Mice. In the present study, the therapeutic effect of QD was assessed in a murine model of DSS-induced colitis. As shown in Figure 1, oral administration of QD greatly rescued the body loss (Figure 1(a)), as well as significantly reduced DAI (Figure 1(b)), a clinical parameter reflecting the severity of weight loss, rectal bleeding, and stool consistency, compared to the DSS model group ( $p<.05$ and $p<.01$, respectively), which even showed a comparative effect with SASP, a first-line drug for UC at a dosage of $0.2 \mathrm{~g} / \mathrm{kg}$. In addition, mice with DSS-induced colitis exhibited a shortened colon length when compared to the control mice. As shown in Figure 1(c), QD treatment significantly abated the situation of colon shortening $(p<.05)$ and ameliorated histopathological changes such as crypt destruction, epithelial and goblet cell loss, and inflammatory cell infiltration (Figure 1(d)). Compared to the DSS model group, QD-treated groups showed much lower histopathological scores (Figure 1(e)).

3.3. QD Suppressed Colonic Oxidative Status DSS-Induced Colitis in Mice. Oxidative stress is one of the critical patho- genic factors for colonic inflammation, and MPO is known as a promoting agent for oxidative stress. Notably, colonic MPO activity was drastically increased in DSS-treated mice compared with the control mice, which was significantly reversed by QD treatment, as shown in Figure 2(a). Accordingly, the activities of antioxidative enzymes including T-SOD, CAT, and GSH-Px in colon tissues were significantly decreased in DSS-treated mice compared with the control mice. Compared with the DSS group, QD at both dosages significantly increased the activities of T-SOD $(38.63 \pm 5.60$ and $35.83 \pm 5.60$, respectively, vs. $25.14 \pm$ 5.94), CAT $(20.09 \pm 2.73$ and $19.67 \pm 2.30$, respectively, vs. $14.90 \pm 2.40)$, and GSH-Px $(3.50 \pm 0.41$ and $3.36 \pm$ 0.38 , respectively, vs. $2.75 \pm 0.45)$ in the colon of DSStreated mice (Figures 2(b)-2(d)).

3.4. $Q D$ Upregulated AMPK and Nrf-2 Activation in the Colon of DSS-Treated Mice. It has been reported that activation of the AMPK/Nrf-2 pathway reduces intracellular ROS levels to prevent cellular oxidative stress damage [27]. We further examined the effects of QD on the expression of $\mathrm{p}$-AMPK, AMPK, and Nrf-2 in the colon of DSS-treated mice. As shown in Figures 3(a)-3(c), colonic p-AMPK and Nrf-2 expressions were drastically decreased in DSS-treated mice compared with the control mice, but QD treatment could significantly reverse those decreases $(p<.05)$. 


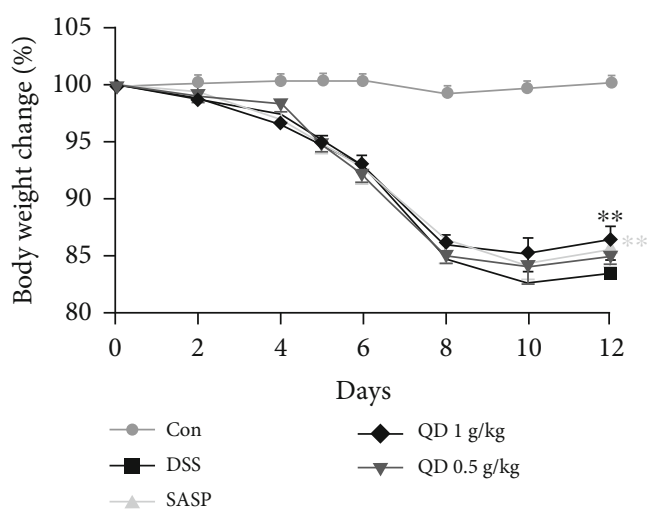

(a)

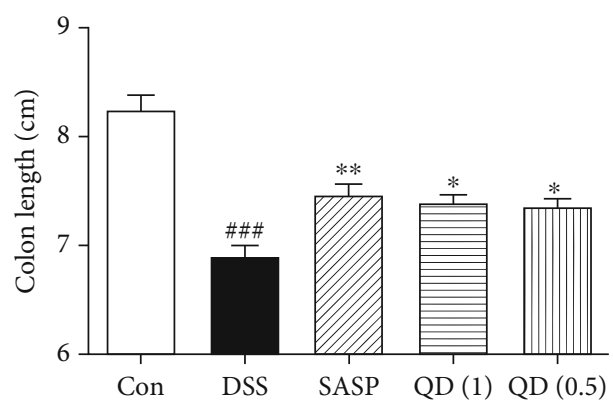

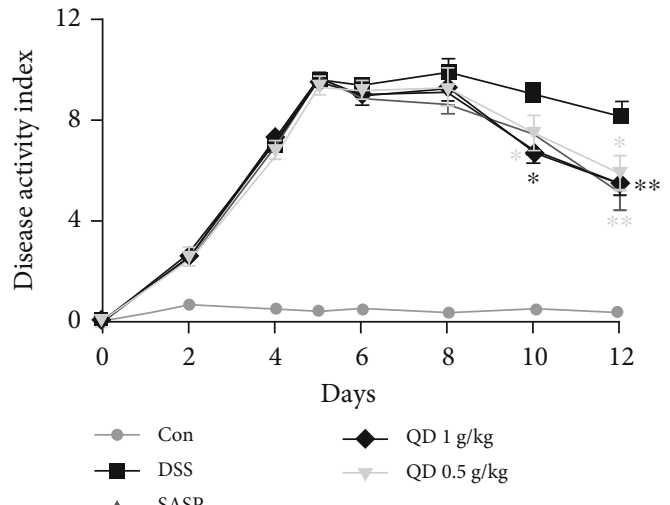

(b)
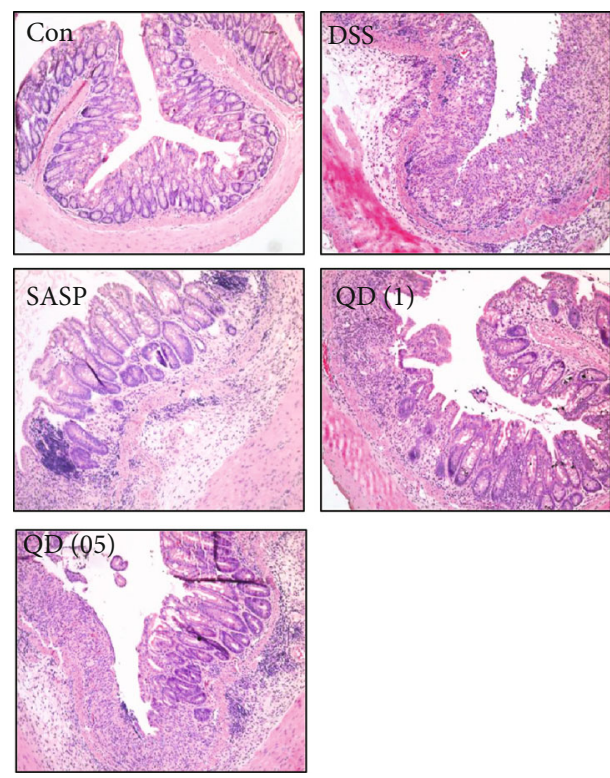

(d)

(c)

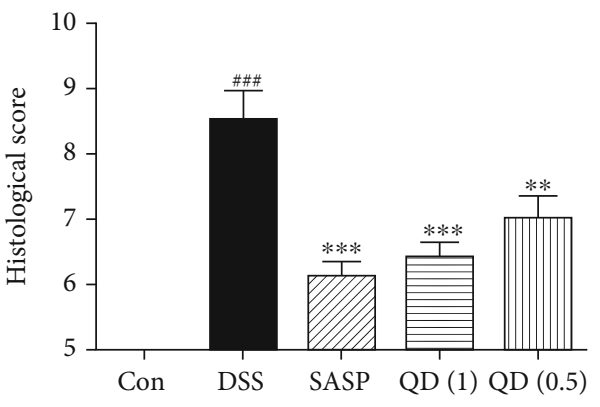

(e)

FIGURE 1: Effects of QD on body loss (a), DAI (b), colon length (c), and histopathological changes (d, e) of mice with DSS-induced colitis. Colitis was induced in all groups except the control group. QD and SASP were administered to mice from days 6 to 12 . The change in body weight was taken as the difference between the body weight before the induction of colitis and that immediately before sacrifice on day 13. The DAI was determined by combining the scores for (1) body weight loss, (2) stool consistency, and (3) stool blood. On day 13, the mice were sacrificed, their colon length was measured, and the colonic tissue damage was evaluated by histopathological analysis (H\&E staining). Data were expressed as mean $\pm \mathrm{SD}(n=6-8) .{ }^{\# \# \#} p<.001$, compared with the control group; ${ }^{*} p<.05,{ }^{* *} p<.01$, and ${ }^{* * *} p<.001$, compared with the DSS model group.

3.5. QD Suppressed the Expression of Th1 and Th17 CellRelated Transcription Factors and Cytokines in the Colon of DSS-Treated Mice. Mice with DSS-induced acute colitis display a Th1/Th17-characterized cytokine pattern, which shows some similarities to the cytokine profile of human IBD [28]. We therefore examined the effects of QD on Th1 and Th17 cell-related transcription factors and cytokines in the colon of DSS-treated mice. As shown in Figure 4(a), the 


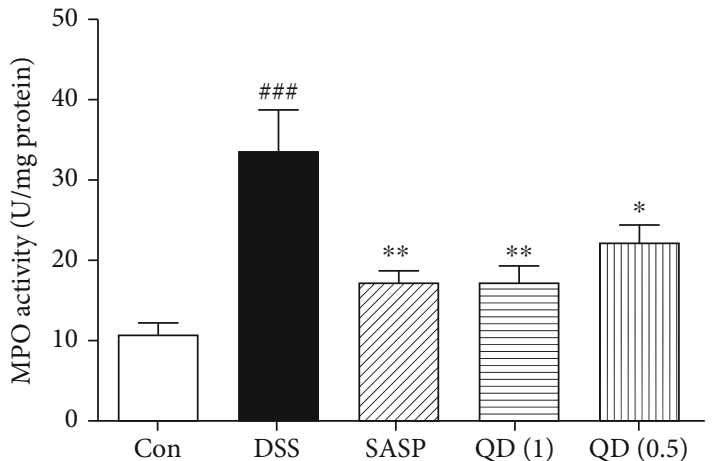

(a)

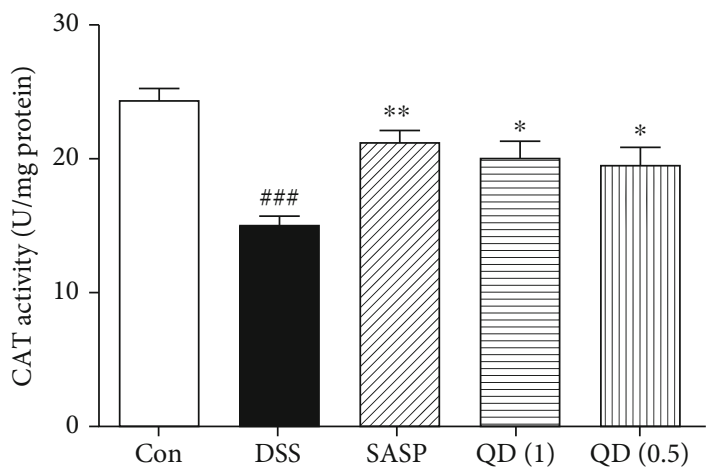

(c)

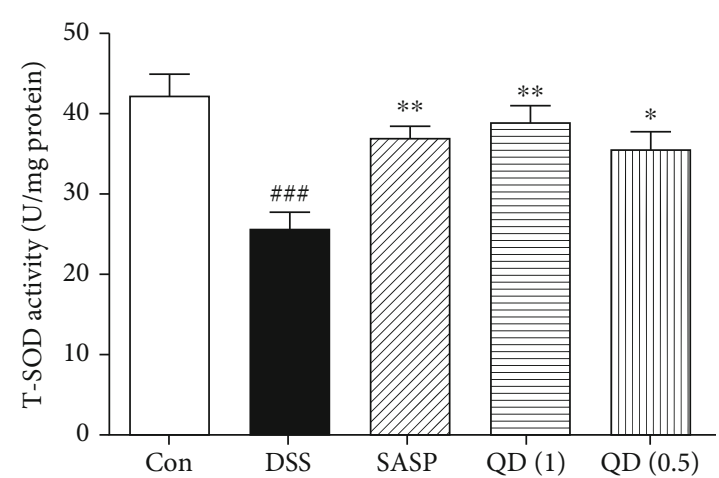

(b)

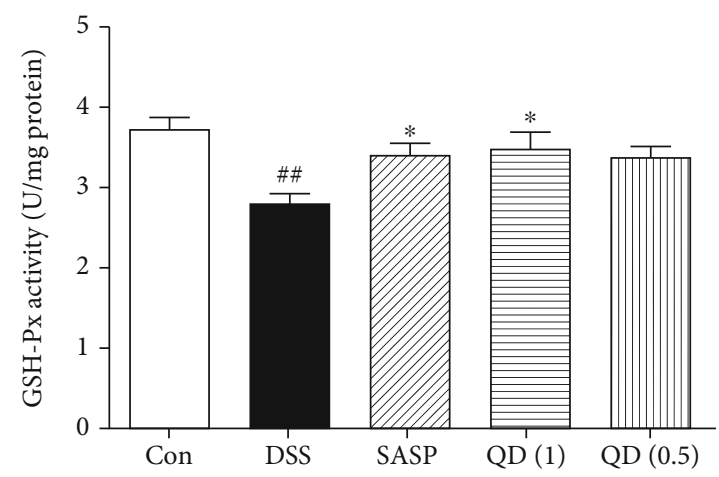

(d)

FIGURE 2: Effects of QD on MPO, T-SOD, GSH-Px, and CAT activities in colon tissues of mice with DSS-induced colitis. Colitis was induced in all groups except the control group. QD and SASP were administered to mice from days 6 to 12 . On day 13, the mice were sacrificed and the MPO, T-SOD, GSH-Px, and CAT activities in the colon tissues were measured. Data were expressed as mean \pm SD $(n=6-8)$. ${ }^{\# \#} p<.01$ and $\# \# p<.001$, compared with the control group; ${ }^{*} p<.05$ and ${ }^{* *} p<.01$, compared with the DSS model group.

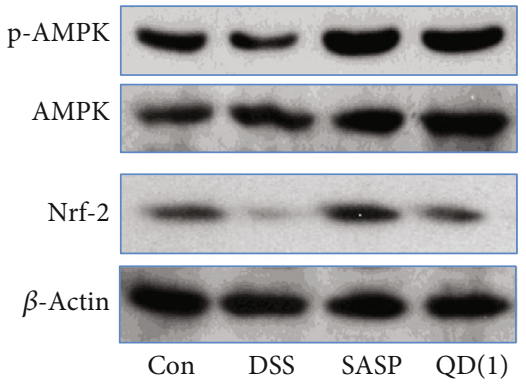

(a)

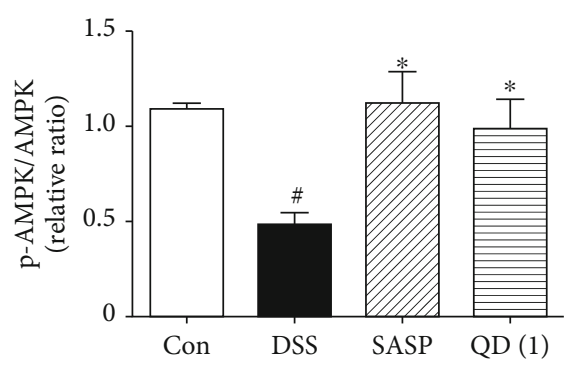

(b)

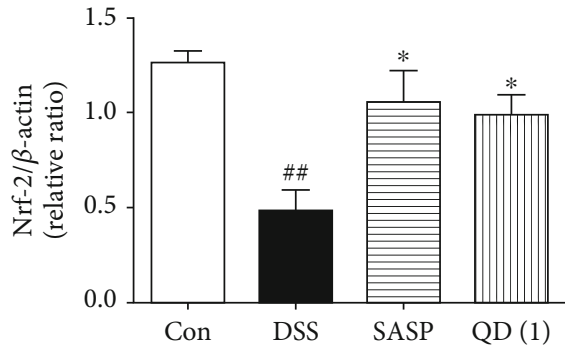

(c)

FIGURE 3: Effects of QD on the expression of p-AMPK, AMPK, and Nrf-2 in colon tissues of mice with DSS-induced colitis. Colitis was induced in all groups except the control group. QD and SASP were administered to mice from days 6 to 12 . On day 13, the mice were sacrificed and the expressions of p-AMPK, AMPK, and Nrf-2 in colon tissues were measured using Western blots. Data were expressed as mean \pm SD $(n=3-4) .{ }^{\#} p<.05$ and ${ }^{\# \#} p<.01$, compared with the control group; ${ }^{*} p<.05$, compared with the DSS model group.

mRNA expression of IFN- $\gamma$, IL-17A, T-bet, and ROR $\gamma \mathrm{t}$ was remarkably induced by DSS. By contrast, the increased mRNA expression of IFN- $\gamma$, IL-17A, T-bet, and ROR $\gamma$ t following DSS treatment were significantly decreased after receiving QD treatment. In parallel, the augmented levels of proinflammatory cytokines IFN- $\gamma$, IL-17A/F, TNF- $\alpha$, and IL- $1 \beta$ in the colon of DSS-treated mice were also significantly suppressed by QD treatment $(p<.01)$ (as shown in Figure 4(b)).
3.6. QD Reduced the Frequencies of Th1 and Th17 Cells in Mesenteric Lymph Nodes of DSS-Treated Mice. Since previous results showed that QD affected the expression of Th1 and Th17 cell-related transcription factors and cytokines in the colon of DSS-treated mice, we further examined the effects of QD on the frequencies of Th1 and Th17 cells in mesenteric lymph nodes. As shown in Figure 5, the frequencies of Th1 and Th17 cells in mesenteric lymph nodes were remarkably increased after DSS treatment $(p<.05$ 

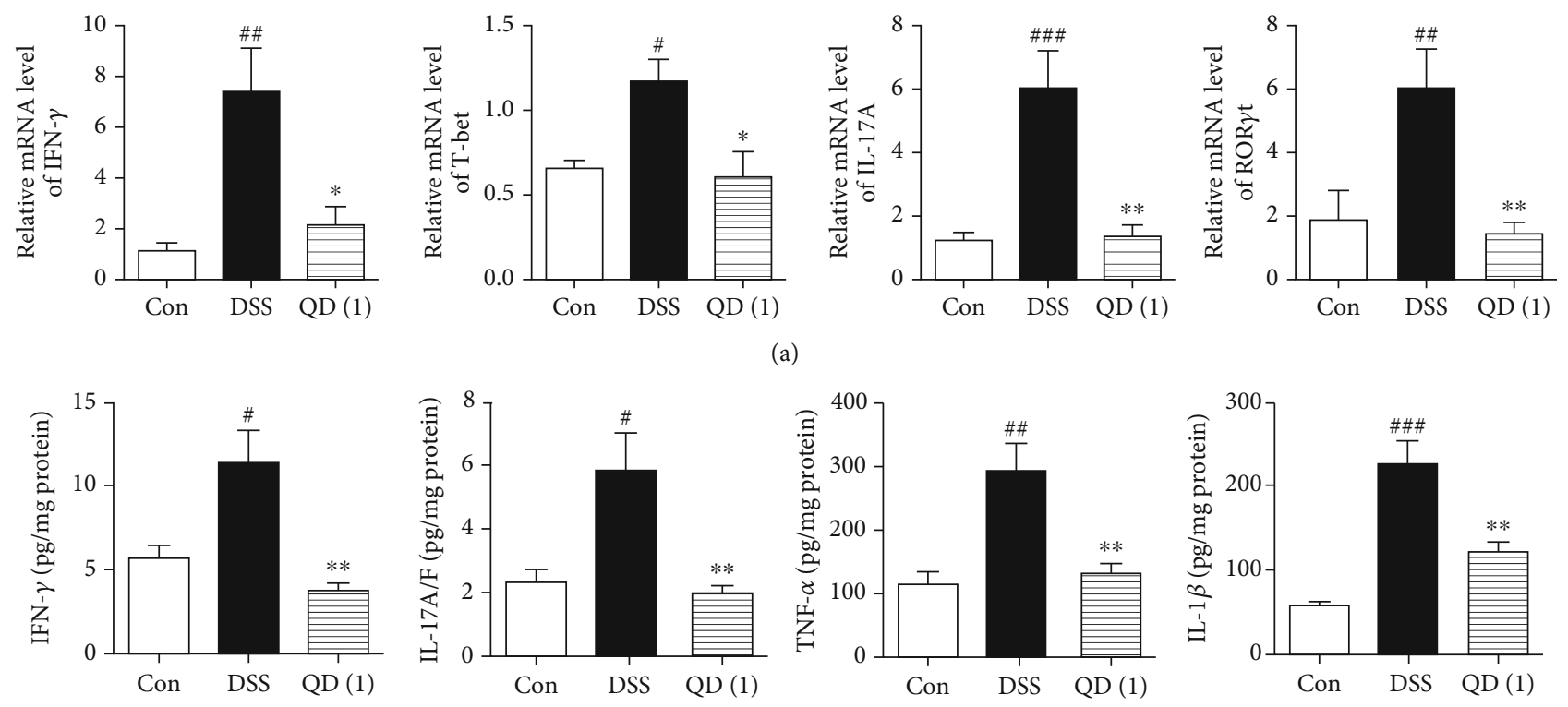

(a)
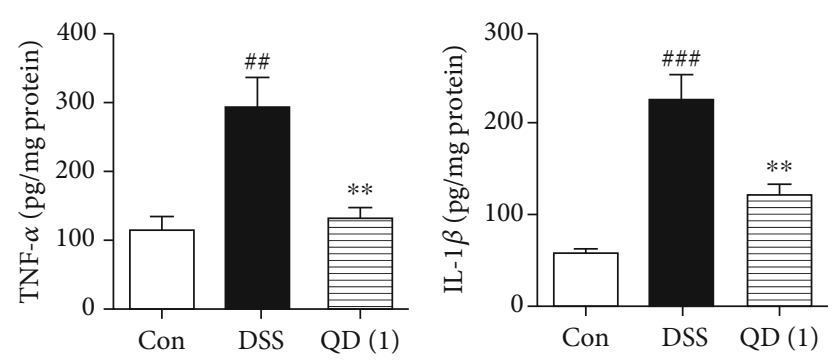

(b)

FIgURE 4: Effects of QD on mRNA and protein expression of Th1/Th17-related cytokines and transcription factors in colon tissues of mice with DSS-induced colitis: (a) mRNA expression of IFN- $\gamma$, T-bet, IL-17A, and ROR $\gamma$ t; (b) protein expression of IFN- $\gamma$, IL-17A/F, TNF- $\alpha$, and IL-1 $\beta$. Colitis was induced in all groups except the control group. QD and SASP were administered to mice from days 6 to 12 . On day 13, the mice were sacrificed and mRNA expressions of IFN- $\gamma$, T-bet, IL-17A, and ROR $\gamma t$ in the colon tissues were measured using RT-PCR. Protein expressions of IFN- $\gamma$, IL-17A/F, TNF- $\alpha$, and IL- $1 \beta$ in the colon tissues were measured using ELISA. Data were expressed as mean \pm SD $(n=6-8) .{ }^{\#} p<.05,{ }^{\# \#} p<.01$, and ${ }^{\# \#} p<.001$, compared with the control group; ${ }^{*} p<.05$ and ${ }^{* *} p<.01$, compared with the DSS model group.

and $p<.001$, respectively). By contrast, the increased Th1 and Th17 cells were greatly decreased after QD administration $(p<.05)$ (Figures 5(a) and 5(b)). However, the frequency of $\mathrm{CD}^{+} \mathrm{FoxP}_{3}{ }^{+}$cells did not show any significant changes after the DSS challenge and QD treatment (Figure 5(c)).

3.7. QD Suppressed p-STAT1 and p-STAT3 Phosphorylation in the Mesenteric Lymph Nodes of DSS-Treated Mice. STAT1 and STAT3 are the crucial transcription factors for Th1 and Th17 responses, respectively [28]. We thus examined the effects of QD on the expression of p-STAT1, STAT1, p-STAT3, and STAT3 in the mesenteric lymph nodes of DSS-treated mice. Notably, DSS treatment significantly increased p-STAT1 and p-STAT3 phosphorylation in the mesenteric lymph nodes of mice, and QD administration could significantly inhibit their activation (as shown in Figures 6(a)-6(c)).

3.8. QD Suppressed Th1 and Th17 Cell Differentiation In Vitro. To further investigate the protective mechanism of QD against Th1 and Th17 cells, we examined the effects of QD on Th1 and Th17 cell differentiation. The results showed that QD at dosages of 250 and $500 \mu \mathrm{g} / \mathrm{mL}$ could significantly inhibit Th1 and Th17 cells differentiation (Figures $7(a)$ and $7(b)$ ).

\section{Discussion}

Despite the increased incidences of IBD, there is still no curative therapy for IBD, and current treatments that focus mainly on relieving symptoms often have little beneficial effect or unwanted side effects. When concerning the helplessness of chemical drugs, IBD patients naturally prefer to seek help from traditional herbal medicine (THM), since they believe that the ingredients of THM are all biological, organic, and natural materials that are mostly harmless to humans [29]. QD, as one of most famous heat-clearing and detoxicating THMs, is often prescribed to IBD patients. Although QD is clinically effective, its action mechanisms remain unclear. In the present study, we showed that QD exhibits a potent anticolitis effect in mice with experimental colitis by suppressing colonic oxidative stress and restraining colonic Th1/Th17 responses, which are associated with activating AMPK/Nrf-2 signals and inhibiting STAT1/STAT3 signals, respectively.

It is well known that oxidative stress is a mechanism underlying the pathophysiology of IBD. With the production of excessive ROS, the endogenous self-antioxidant defenses would be overwhelmed, resulting in mucosal disruption and ulceration with infiltration of massive inflammatory cells in the colon tissues [7]. MPO is a marker of tissue injury and neutrophil infiltration, as well as a promoting agent for oxidative stress [30]. Previous studies have well documented that the increase of MPO is closely linked to the severity of IBD $[23,30,31]$. In the present study, we found that colonic MPO activity in DSS-treated mice was drastically increased compared with the control mice, indicating extensive neutrophil infiltration into the colonic tissues. In addition, the infiltration of massive inflammatory cells, such as neutrophils within the mucosa, produced and released a large amount of ROS in an uncontrolled manner. Highly localized 

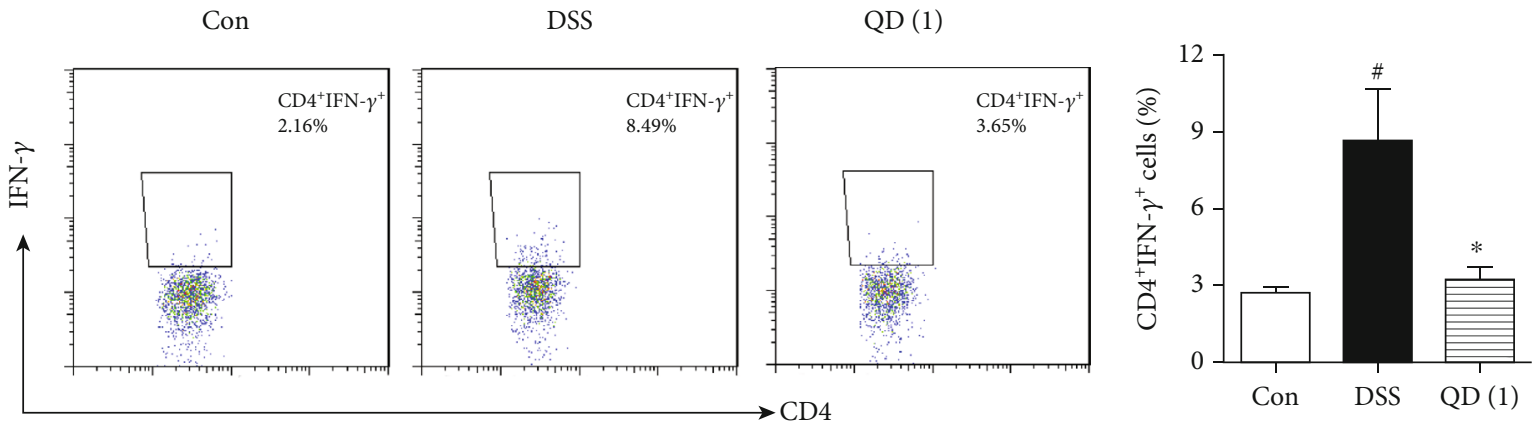

(a)
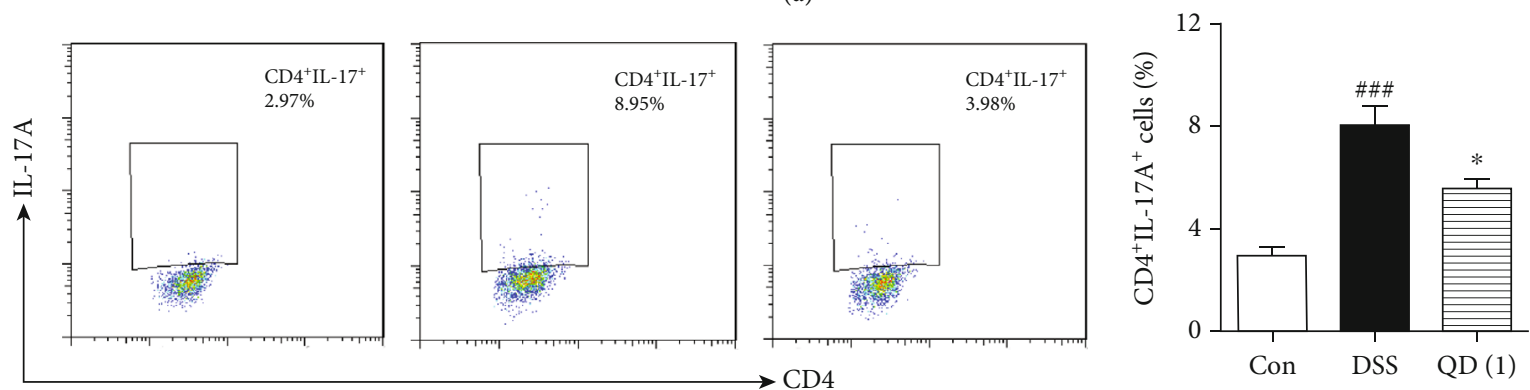

(b)
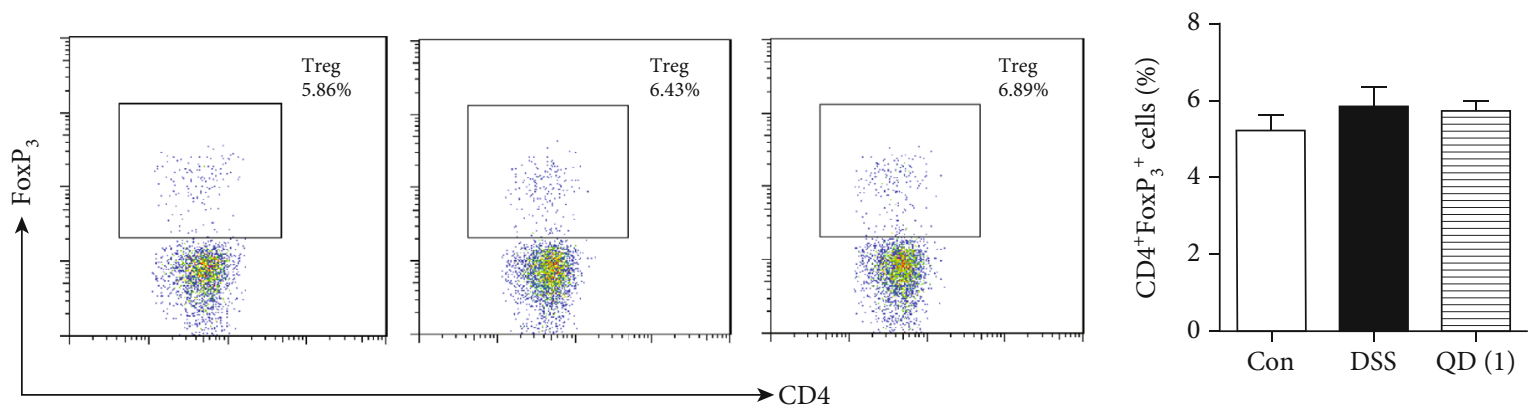

(c)

FIgURE 5: Effects of QD on the frequencies of Th1 (a), Th17 (b), and Treg (c) cells in mesenteric lymph nodes of mice with DSS-induced colitis. Colitis was induced in all groups except the control group. QD was administered to mice from days 6 to 12 . On day 13, the mice were sacrificed and the frequencies of Th1, Th17, and Treg cells in mesenteric lymph nodes were measured using flow cytometry. Data were expressed as mean \pm SD $(n=6-8) .{ }^{\#} p<.05$ and ${ }^{\# \# \#} p<.001$, compared with the control group; ${ }^{*} p<.05$, compared with the DSS model group.

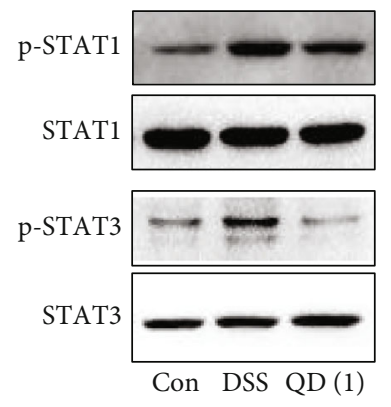

(a)

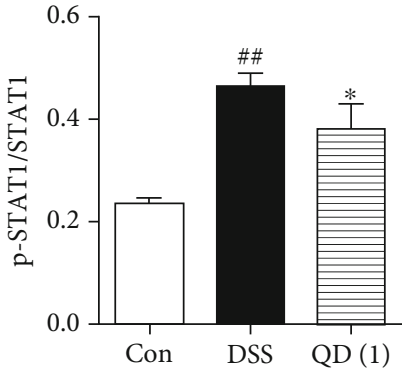

(b)

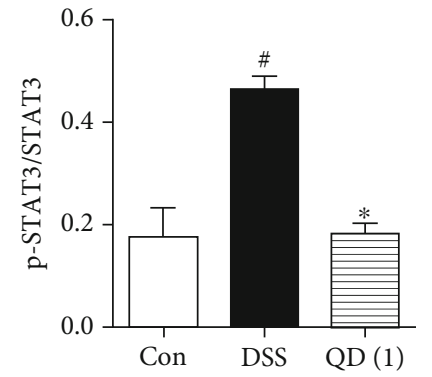

(c)

FIGURE 6: Effects of QD on the phosphorylation of p-STAT1 and p-STAT3 in mesenteric lymph nodes of mice with DSS-induced colitis. Colitis was induced in all groups except the control group. QD was administered to mice from days 6 to 12. On day 13, the mice were sacrificed and the expressions of p-STAT1, STAT1, p-STAT3, and STAT3 in mesenteric lymph nodes were measured using Western blots. Data were expressed as mean \pm SD $(n=3-4) .{ }^{\#} p<.05$ and ${ }^{\# \#} p<.01$, compared with the control group; ${ }^{*} p<.05$, compared with the DSS model group. 

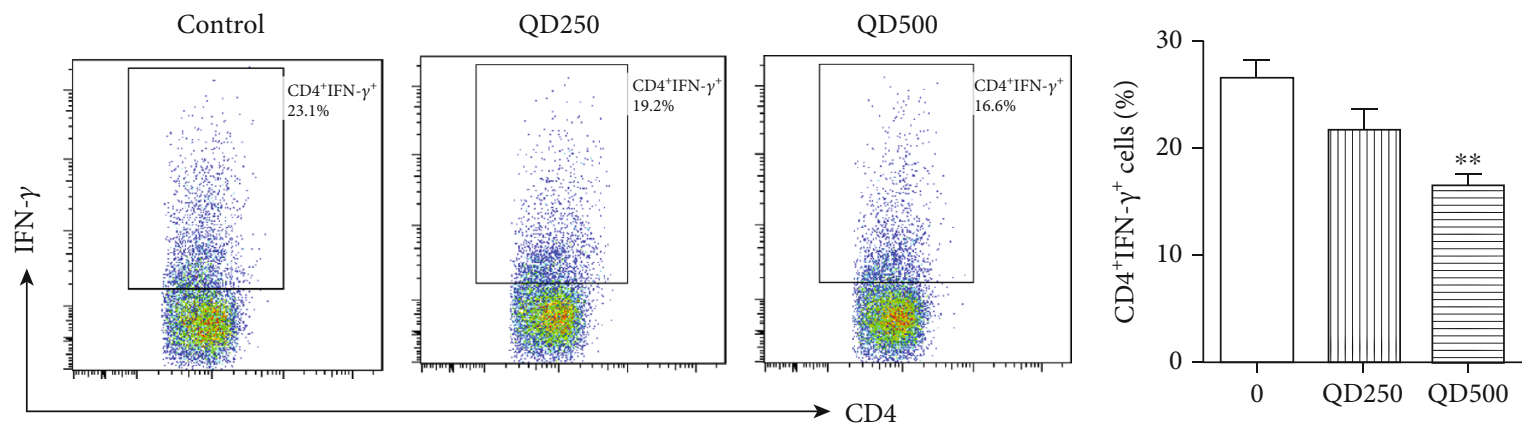

(a)
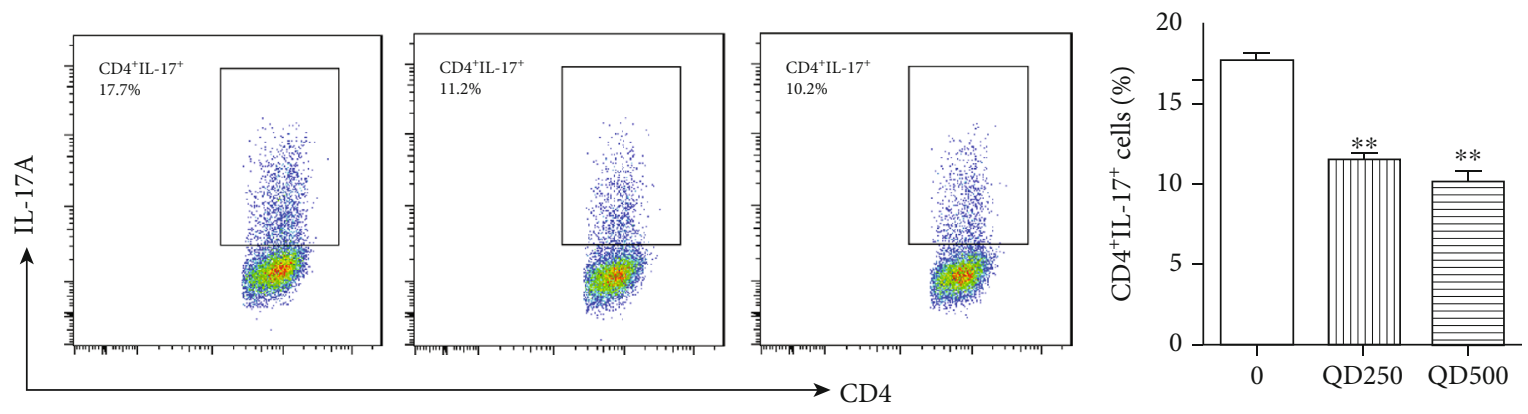

(b)

FIgURE 7: Effects of QD on Th1 (a) and Th17 (b) differentiation in vitro. Naïve CD4 T cells from C57BL/6 mice were incubated under Th1 or Th17 polarizing conditions in the presence or absence of indicated concentrations of QD with anti-CD3/CD28 stimulation for three days. The phenotypes of Th1 and Th17 cells were analyzed using flow cytometry. Data were expressed as mean $\pm \mathrm{SD}(n=3) .{ }^{* *} p<.01$, compared with the control group.

concentrations of ROS could attack and inactivate endogenous antioxidant defenses, such as GSH-Px, T-SOD, and CAT, thus preventing the neutralization of $\operatorname{ROS}[32,33]$. We also observed a decrease in colonic GSH-Px, T-SOD, and CAT activities in DSS-treated mice compared with those in the control mice, which were consistent with previous reports [32, 34]. Notably, administration of QD significantly restrained the elevation of colonic MPO activity and decreased colonic GSH-Px, T-SOD, and CAT activities in DSS-treated mice. Also, previous studies have revealed that QD administration significantly suppressed inflammations by scavenging ROS in UC patients and attenuated the ROS production from the NSAID-induced mitochondrial alteration in the gastrointestinal epithelial cells $[16,35]$. Taken together, these findings indicate that QD is effective for inhibiting oxidative stress and boosting antioxidant defenses.

Recent evidence has indicated that AMPK activation plays pivotal roles in regulating epithelial functions in experimental colitis in mice, and activation of the AMPK pathway reduces intracellular ROS levels to prevent cellular oxidative stress damage $[27,36]$. Nuclear factor erythroid 2-related factor 2 (Nrf-2) was considered important for protecting against the oxidative stress in cells, which is regulated by AMPK [27, 37]. Previous studies have reported a significant decrease in the mRNA and protein expressions of Nrf- 2 and $\mathrm{p}$-AMPK in the colon tissues of various experimental colitis, showing that reversing the decrease of Nrf-2 or p-AMPK ameliorates colitis [27, 36, 38, 39]. Our data demonstrated that DSS treatment significantly decreased the expression of Nrf- 2 or p-AMPK in the colon tissues, which can be effectively reversed by QD administration. These results indicate that the antioxidative potential of QD on DSS-induced colitis was attributed to activating the AMPK/Nrf-2 signaling pathway.

Excessive effector T cells such as Th1 and Th17 cells are major players in the disease process, and targeting Th1/Th17 to attenuate the severity of IBD has been well documented [40]. To mimic this disease in mice, DSS-induced colitis is a well-established animal model, which displays a predominant cytokine pattern of a Th1/Th17 type closely resembling those in IBD patients [28]. Using this model, we found that QD could greatly suppress the gene expression of Th1 and Th17 cell cytokines IFN- $\gamma$ and IL-17A and their transcription factors T-bet and $\mathrm{ROR} \gamma \mathrm{t}$, as well as the production of Th1/Th17-related cytokines, namely, IFN- $\gamma$, IL$17 \mathrm{~A} / \mathrm{F}, \mathrm{TNF}-\alpha$, and IL- $1 \beta$. Moreover, flow cytometric detection showed that both Th1 $\left(\mathrm{CD} 4^{+}\right.$IFN $\left.-\gamma^{+}\right)$and Th17 $\left(\mathrm{CD} 4^{+} \mathrm{IL}-17 \mathrm{~A}^{+}\right)$cells in mesenteric lymph nodes of DSStreated mice and the differentiation of Th1 and Th17 cells in vitro were significantly reduced after QD treatment. These results clearly revealed that QD suppresses Th1/Th17 responses in DSS-induced colitis.

STATs are a family of nuclear proteins mediating the actions of numerous cytokines. Among them, STAT1 plays a critical role in the signal transduction pathway of IFN- $\gamma$, which drives Th1 cell differentiation and activation [41], and STAT3 is a crucial transcription factor for Th17 cell development and in regulating the production of IL-17A [28]. Our data demonstrated that the phosphorylation of p-STAT1 and p-STAT3 in the mesenteric lymph nodes 
of DSS-induced colitic mice was significantly increased compared with the expression in the control mice. Additionally, QD could greatly suppress activation of both STAT1 and STAT3, indicating that suppressing STAT1 and STAT3 activation could contribute to the inhibitory effects of QD on Th1/Th17 responses.

\section{Conclusion}

The present study demonstrates that QD exhibits a potent therapeutic effect on DSS-induced colitis, which may be associated with suppressing colonic oxidative stress and restraining colonic Th1/Th17 responses, which are associated with activating AMPK/Nrf-2 signaling pathways and inhibiting STAT1/STAT3 signaling pathways, respectively. These findings support that $\mathrm{QD}$ is an effective regimen for the treatment of IBD.

\section{Data Availability}

The data used or analyzed during the current study are available from the corresponding authors on reasonable request.

\section{Conflicts of Interest}

The authors declare that they have no conflicts of interest.

\section{Acknowledgments}

This research was partly based on the thesis of Dr. Haitao Xiao and supported by the National Natural Science Foundation of China (No. 81560676), the Peacock Program for Overseas High-Level Talents of Shenzhen, the launching fund of the Scientific Research for New Teachers of Shenzhen University (no. 2018020), and the Shenzhen Science and Technology Innovation Committee Grant (No. JCYJ20170413170320959) and partly supported by the National Key R\&D Program of China (No. 2017YFA053900) and the National Natural Science Foundation of China (Nos. 31670360 and U1702286).

\section{Supplementary Materials}

Supplementary Figure 1: total ion chromatograms (TICs) in the positive mode of the QD extract. (Supplementary Materials)

\section{References}

[1] H. T. Xiao, B. Wen, X. C. Shen, and Z. X. Bian, "Potential of plant-sourced phenols for inflammatory bowel disease," Current Medicinal Chemistry, vol. 25, no. 38, pp. 5191-5217, 2018.

[2] A. Lan, F. Blachier, R. Benamouzig et al., "Mucosal healing in inflammatory bowel diseases: is there a place for nutritional supplementation?," Inflammatory Bowel Diseases, vol. 21, no. 1, pp. 198-207, 2015.

[3] S. C. Ng, H. Y. Shi, N. Hamidi et al., "Worldwide incidence and prevalence of inflammatory bowel disease in the 21 st century: a systematic review of population-based studies," Lancet, vol. 390, no. 10114, pp. 2769-2778, 2018.
[4] G. Cui and A. Yuan, "A systematic review of epidemiology and risk factors associated with Chinese inflammatory bowel disease," Frontiers in Medicine, vol. 5, p. 183, 2018.

[5] N. J. Talley, M. T. Abreu, J. P. Achkar et al., "An evidencebased systematic review on medical therapies for inflammatory bowel disease," American Journal of Gastroenterology, vol. 106, pp. S2-S25, 2011.

[6] M. Coskun, C. Steenholdt, N. K. de Boer, and O. H. Nielsen, "Pharmacology and optimization of thiopurines and methotrexate in inflammatory bowel disease," Clinical Pharmacokinetics, vol. 55, no. 3, pp. 257-274, 2016.

[7] T. Tian, Z. Wang, and J. Zhang, "Pathomechanisms of oxidative stress in inflammatory bowel disease and potential antioxidant therapies," Oxidative Medicine and Cellular Longevity, vol. 2017, Article ID 4535194, 18 pages, 2017.

[8] Z. Wang, S. Li, Y. Cao et al., "Oxidative stress and carbonyl lesions in ulcerative colitis and associated colorectal cancer," Oxidative Medicine and Cellular Longevity, vol. 2016, Article ID 9875298, 15 pages, 2016.

[9] T. Imam, S. Park, M. H. Kaplan, and M. R. Olson, "Effector T helper cell subsets in inflammatory bowel diseases," Frontiers in Immunology, vol. 9, p. 1212, 2018.

[10] B. Shin, R. L. Kress, P. A. Kramer, V. M. Darley-Usmar, S. L. Bellis, and L. E. Harrington, "Effector CD4 T cells with progenitor potential mediate chronic intestinal inflammation," The Journal of Experimental Medicine, vol. 215, no. 7, p. jem.20172335, 2018.

[11] H. Cui, Y. Cai, L. Wang et al., "Berberine regulates Treg/Th17 balance to treat ulcerative colitis through modulating the gut microbiota in the colon," Frontiers in Pharmacology, vol. 9, pp. 571-571, 2018.

[12] J. Su, C. Li, X. Yu et al., "Protective effect of pogostone on 2,4,6trinitrobenzenesulfonic acid-induced experimental colitis via inhibition of T helper cell," Frontiers in Pharmacology, vol. 8, pp. 829-829, 2017.

[13] S. Hu, M. Chen, Y. Wang et al., "mTOR inhibition attenuates dextran sulfate sodium-induced colitis by suppressing $\mathrm{T}$ cell proliferation and balancing TH1/TH17/Treg profile," PLoS One, vol. 11, no. 4, article e0154564, 2016.

[14] Y. R. Chiang, A. Li, Y. L. Leu, J. Y. Fang, and Y. K. Lin, “An in vitro study of the antimicrobial effects of indigo naturalis prepared from Strobilanthes formosanus Moore," Molecules, vol. 18, no. 11, pp. 14381-14396, 2013.

[15] Y. K. Lin, H. W. Chen, Y. L. Leu et al., "Indigo naturalis upregulates claudin-1 expression in human keratinocytes and psoriatic lesions," Journal of Ethnopharmacology, vol. 145, no. 2, pp. 614-620, 2013.

[16] H. Suzuki, T. Kaneko, Y. Mizokami et al., "Therapeutic efficacy of the Qing Dai in patients with intractable ulcerative colitis," World Journal of Gastroenterology, vol. 19, no. 17, pp. 27182722, 2013.

[17] G. Yuan, Q. Ke, X. Su, J. Yang, and X. Xu, "Qing Dai, a traditional Chinese medicine for the treatment of chronic hemorrhagic radiation proctitis," The Chinese-German Journal of Clinical Oncology, vol. 8, no. 2, pp. 114-116, 2009.

[18] M. Naganuma, S. Sugimoto, K. Mitsuyama et al., "Efficacy of indigo naturalis in a multicenter randomized controlled trial of patients with ulcerative colitis," Gastroenterology, vol. 154, no. 4, pp. 935-947, 2018.

[19] H. T. Xiao, J. Peng, D. D. Hu et al., "Qing-dai powder promotes recovery of colitis by inhibiting inflammatory responses 
of colonic macrophages in dextran sulfate sodium-treated mice," Chinese Medicine, vol. 10, no. 1, 2015.

[20] S. Kawai, H. Iijima, S. Shinzaki et al., "Indigo naturalis ameliorates murine dextran sodium sulfate-induced colitis via aryl hydrocarbon receptor activation," Journal of Gastroenterology, vol. 52, no. 8, pp. 904-919, 2017.

[21] Commission CP, "Pharmacopoeia of the People's Republic of China," in Indigo naturalis. Edited by Commission CP, Chemical Industry Press, Beijing, 2010.

[22] H. T. Xiao, S. W. Tsang, H. Y. Qin et al., "A bioactivity-guided study on the anti-diarrheal activity of Polygonum chinense Linn," Journal of Ethnopharmacology, vol. 149, no. 2, pp. 499-505, 2013.

[23] H. T. Xiao, C. Y. Lin, D. H. H. Ho et al., "Inhibitory effect of the gallotannin corilagin on dextran sulfate sodium-induced murine ulcerative colitis," Journal of Natural Products, vol. 76, no. 11, pp. 2120-2125, 2013.

[24] J. M. Kim, H. W. Kang, M. Y. Cha et al., "Novel guggulsterone derivative GG-52 inhibits NF-kappaB signaling in intestinal epithelial cells and attenuates acute murine colitis," Laboratory Investigation, vol. 90, no. 7, pp. 1004-1015, 2010.

[25] K. Singh, A. S. Jaggi, and N. Singh, "Exploring the ameliorative potential of Punica granatum in dextran sulfate sodium induced ulcerative colitis in mice," Phytotherapy Research, vol. 23, no. 11, pp. 1565-1574, 2009.

[26] J. Adamec, A. Jannasch, J. Huang et al., "Development and optimization of an LC-MS/MS-based method for simultaneous quantification of vitamin D2, vitamin D3, 25hydroxyvitamin D2 and 25-hydroxyvitamin D3," Journal of Separation Science, vol. 34, no. 1, pp. 11-20, 2011.

[27] K. Zhou, R. Cheng, B. Liu, L. Wang, H. Xie, and C. Zhang, "Eupatilin ameliorates dextran sulphate sodium-induced colitis in mice partly through promoting AMPK activation," Phytomedicine, vol. 46, pp. 46-56, 2018.

[28] F. Tao, C. Qian, W. Guo, Q. Luo, Q. Xu, and Y. Sun, "Inhibition of Th1/Th17 responses via suppression of STAT1 and STAT3 activation contributes to the amelioration of murine experimental colitis by a natural flavonoid glucoside icariin," Biochemical Pharmacology, vol. 85, no. 6, pp. 798-807, 2013.

[29] H. T. Xiao, L. Zhong, S. W. Tsang, Z. S. Lin, and Z. X. Bian, "Traditional Chinese medicine formulas for irritable bowel syndrome: from ancient wisdoms to scientific understandings," The American Journal of Chinese Medicine, vol. 43, no. 01, pp. 1-23, 2015.

[30] X. He, Z. Wei, J. Wang et al., “Alpinetin attenuates inflammatory responses by suppressing TLR4 and NLRP3 signaling pathways in DSS-induced acute colitis," Scientific Reports, vol. 6 , no. $1,2016$.

[31] N. Yang, Z. Xia, N. Shao et al., "Carnosic acid prevents dextran sulfate sodium-induced acute colitis associated with the regulation of the Keap1/Nrf2 pathway," Scientific Reports, vol. 7, no. 1, p. 11036, 2017.

[32] G. Liu, L. Yu, J. Fang et al., "Methionine restriction on oxidative stress and immune response in DSS-induced colitis mice," Oncotarget, vol. 8, no. 27, pp. 44511-44520, 2017.

[33] J. Yin, J. Duan, Z. Cui, W. Ren, T. Li, and Y. Yin, "Hydrogen peroxide-induced oxidative stress activates NF- $\kappa \mathrm{B}$ and Nrf2/Keap1 signals and triggers autophagy in piglets," $R S C$ Advances, vol. 5, no. 20, pp. 15479-15486, 2015.

[34] B. Liu, S. Li, X. Sui et al., "Root extract of Polygonum cuspidatum Siebold \& Zucc. ameliorates DSS-induced ulcerative coli- tis by affecting NF-kappaB signaling pathway in a mouse model via synergistic effects of polydatin, resveratrol, and emodin," Frontiers in Pharmacology, vol. 9, 2018.

[35] R. Saito, M. Tamura, H. Matsui et al., "Qing Dai attenuates nonsteroidal anti-inflammatory drug-induced mitochondrial reactive oxygen species in gastrointestinal epithelial cells," Journal of Clinical Biochemistry and Nutrition, vol. 56, no. 1, pp. 8-14, 2015.

[36] L. Chen, J. Wang, Q. You et al., “Activating AMPK to restore tight junction assembly in intestinal epithelium and to attenuate experimental colitis by metformin," Frontiers in Pharmacology, vol. 9, p. 761, 2018.

[37] C. Zhao, Y. Zhang, H. Liu, P. Li, H. Zhang, and G. Cheng, "Fortunellin protects against high fructose-induced diabetic heart injury in mice by suppressing inflammation and oxidative stress via AMPK/Nrf-2 pathway regulation," Biochemical and Biophysical Research Communications, vol. 490, no. 2, pp. 552-559, 2017.

[38] S. Saber, R. M. Khalil, W. S. Abdo, D. Nassif, and E. elAhwany, "Olmesartan ameliorates chemically-induced ulcerative colitis in rats via modulating $\mathrm{NF} \kappa \mathrm{B}$ and $\mathrm{Nrf}-2 / \mathrm{HO}-1$ signaling crosstalk," Toxicology and Applied Pharmacology, vol. 364, pp. 120-132, 2019.

[39] X. Ma, Y. Hu, X. Li et al., "Periplaneta americana ameliorates dextran sulfate sodium-induced ulcerative colitis in rats by Keap1/Nrf-2 activation, intestinal barrier function, and gut microbiota regulation," Frontiers in Pharmacology, vol. 9, p. 944, 2018.

[40] W. Liu, W. Guo, L. Guo et al., “Andrographolide sulfonate ameliorates experimental colitis in mice by inhibiting Th1/Th17 response," International Immunopharmacology, vol. 20, no. 2, pp. 337-345, 2014.

[41] J. Wang, X. Niu, C. Wu, and D. Wu, "Naringenin modifies the development of lineage-specific effector CD4(+) T cells," Frontiers in Immunology, vol. 9, p. 2267, 2018. 


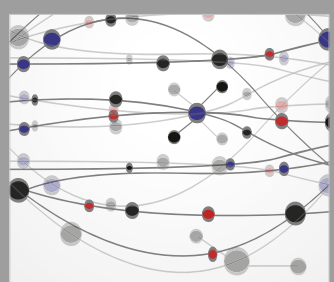

The Scientific World Journal
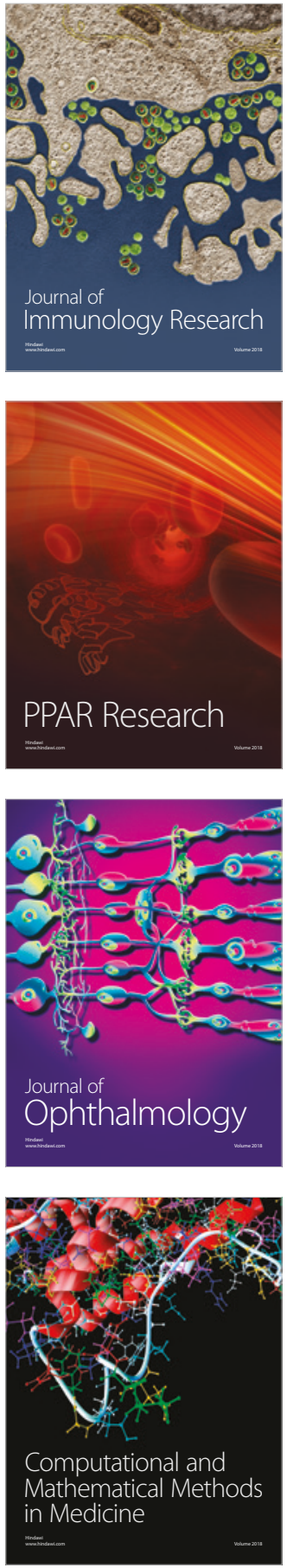

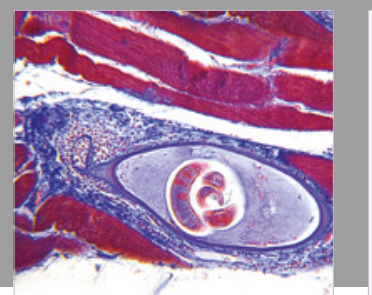

Gastroenterology Research and Practice

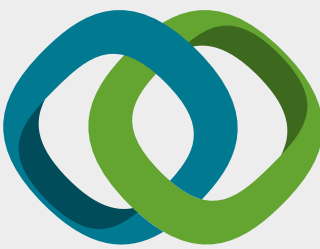

\section{Hindawi}

Submit your manuscripts at

www.hindawi.com
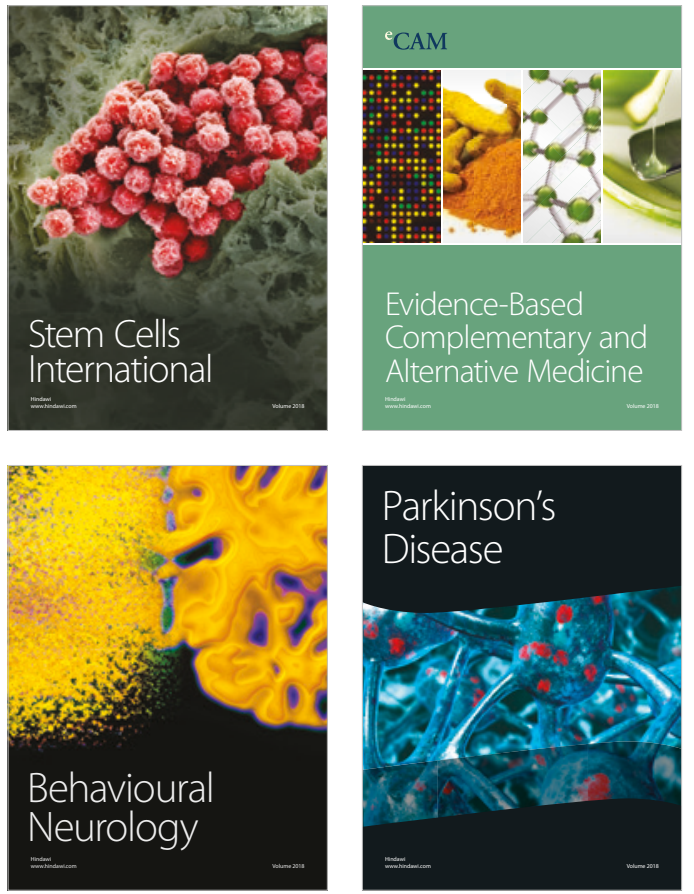

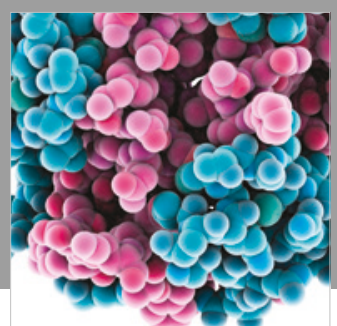

ournal of

Diabetes Research

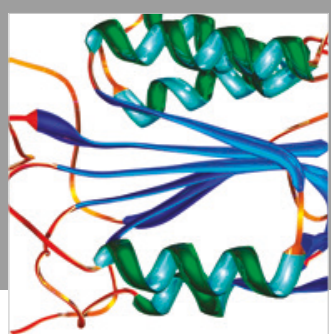

Disease Markers
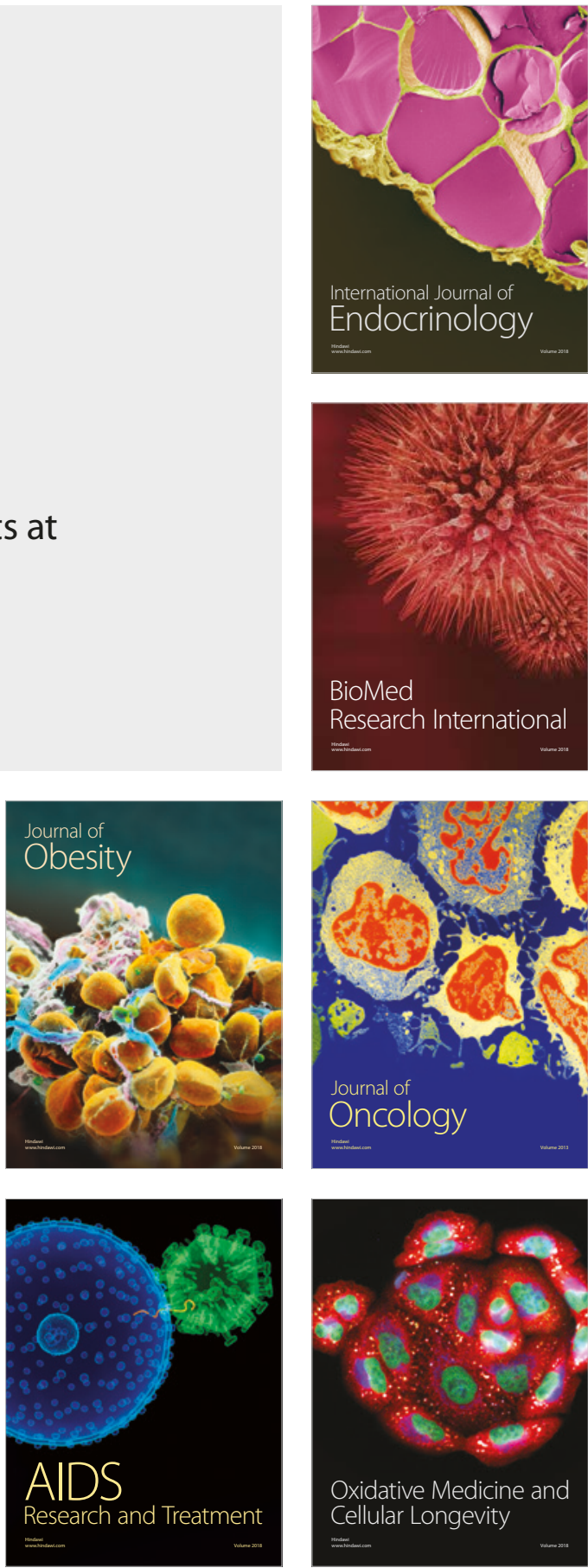